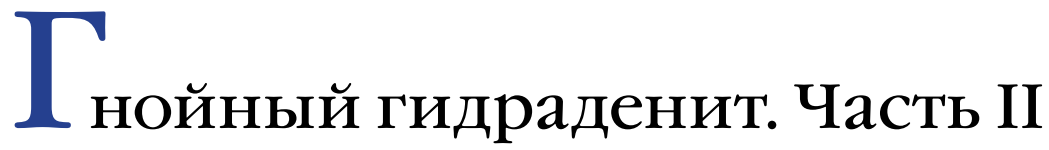

Родионов А. Н. ${ }^{1}$, Соболев А. В. ${ }^{2}$, Скрек С. В. ${ }^{1,3}$, Волькенштейн П. ${ }^{4}$, Юновидова А. А. ${ }^{3}$

${ }^{1}$ Северо-Западный государственный медицинский университет им. И. И. Мечникова Министерства здравоохранения Российской Федерации 195067, Российская Федерация, г. Санкт-Петербург, Кирочная ул., д. 41

${ }^{2}$ Научно-исследовательский институт медицинской микологии им. П. Н. Кашкина Северо-Западного государственного медицинского университета им. И. И. Мечникова Министерства здравоохранения Российской Федерации 194291, Российская Федерация, г. Санкт-Петербург, ул. Сантьяго-де-Куба, д. 1/28

${ }^{3}$ Французская клиника кожных болезней Пьера Волькенштейна 191123, Российская Федерация, г. Санкт-Петербург, ул. Рылеева, д. 24

${ }^{4}$ Дерматологическая служба университетского госпиталя Энри Мондор 94000, Франция, Кретей, авеню Маршала Латтре де Тассиньи, д. 51

Гнойный гидраденит — хроническое рецидивирующее заболевание, поражающее 4\% населения, причиной которого является неконтролируемый рост клеток волосяного фоолликула и апокриновой железы, что приводит к развитию аутоиммунного, а затем септического воспаления. Провоцирующими фракторами являются ожирение, курение, фоорирование апокриновых желез в организме. Многообразие субтипов гнойного гидраденита, различия в прогнозе и течении заболевания, а также необходимость ведения пациентов с данной патологией в хирургическом отделении обусловливают стандартизацию терапевтического алгоритма и объективизацию степени клинического ответа на проводимую терапию с помощью оценочных шкал.

Ключевые слова: гнойный гидраденит, Notch-путь, Th17-клетки, курение, ожирение

Конфрликт интересов: авторы заявляют об отсутствии потенциального конфрликта интересов, требующего раскрытия в данной статье.

Для цитирования: Родионов А. Н., Соболев А. В., Скрек С. В., Волькенштейн П., Юновидова А. А. Гнойный гидраденит. Часть II. Вестник дерматологии и венерологии. 2017;(6):41-46. DOI: 10.25208/0042-4609-2017-93-6$41-46$ 


\section{Purulent Hydradenitis. Part II}

Anatoliy N. Rodionov ${ }^{1}$, Alexey V. Sobolev², Sergey V. Skrek ${ }^{1,3}$, Pierre Wolkenstein ${ }^{4}$, Anastasiya A. Yunovidova ${ }^{3}$

${ }^{1}$ North-Western State Medical University named after I. I. Mechnikov, Ministry of Health of the Russian Federation Kirochnaya str., 41, St. Petersburg, 191015, Russian Federation

${ }^{2}$ Research Institute of Medical Mycology named after P. N. Kashkin of the North-Western State Medical University named after I. I. Mechnikov, Ministry of Health of the Russian Federation

Santiago de Cuba str., 1/28, St. Petersburg, 194291, Russian Federation

${ }^{3}$ The Pierre Wolkenstein French Dermatological Clinic

Ryleeva str., 24, St. Petersburg, 191123, Russian Federation

${ }^{4}$ Dermatological Service of the Henri Mondor University Hospital

Avenue du Maréchal de Lattre de Tassigny, 51, Créteil, 94000, France

Purulent hydradenitis is a chronic relapsing disease that affects $4 \%$ of the population, caused by uncontrolled growth of hair follicle and apocrine gland cells, which leads to the development of autoimmune and then septic inflammation. The provoking factors are obesity, smoking, formation of apocrine glands in the body. The variety of subordinates of Suppurative hydradenitis, differences in the prognosis and course of the disease, as well as the need to manage patients with this pathology in the surgical department, determine the standardization of the therapeutic algorithm and the objectification of the degree of clinical response to the therapy using scoring scales.

Keywords: purulent hydradenitis, Notch pathway, Th17 cells, smoking, obesity

Conflict of interest: the authors state that there is no potential conflict of interest requiring disclosure in this article.

For citation: Rodionov A. N., Sobolev A. V., Skrek S. V., Wolkenstein P., Yunovidova A. A. Purulent Hydradenitis. Part II. Vestnik Dermatologii i Venerologii. 2017;(6):41-46. DOI: 10.25208/0042-4609-2017-93-6-41-46 


\section{Введение}

Гнойный гидраденит - весьма распространенное хроническое рецидивирующее заболевание, патогенез которого связан с нарушением передачи сигнала между клетками волосяного фолликула и апокриновой железы. Это нарушение пути приводит к неконтролируемому клеточному росту и развитию сначала аутоиммунного, а затем и септического воспаления. Специфическая генетическая предрасположенность, фракторы окружающей среды, высокий экономический уровень развития, урбанизация предопределили особый набор триггеров и предикторов в развитии гнойного гидраденита. Биологический прогресс и открытие новых терапевтических возможностей позволили заново взглянуть на проблему врачам различных специальностей, что обусловило необходимость создания стандартизированных методов оценки клинического ответа на проводимую терапию. Оценочные шкалы и их оптимизация являются одной из актуальных проблем мировой дерматологии.

Гнойный гидраденит (син.: инверсные акне, болезнь Вернея, болезнь Вельпо) - хроническое воспалительное рецидивирующее заболевание кожи и ее придатков, манифестирующее после полового созревания и характери- зующееся появлением болезненных, глубоких свищевых ходов в крупных складках кожи (определение Дессау) [1].

Уровень превалентности заболевания составляет 4\% [2].

Патогенез заболевания связан с поломкой сигнального пути Notch, приводящей к неконтролируемому росту клеток, из-за которого происходит дестабилизация, а затем разрыв стенок волосяного влагалища и апокриновой железы. Последующее фрормирование роговых кист и гиперпродукция кератина способствуют развитию аутовоспаления и возникновению септического воспаления в дальнейшем [3].

\section{Факторы риска и коморбидные состояния}

Существенное значение в развитии заболевания имеют факторы риска и коморбидные состояния. Первым термином принято обозначать факторы, увеличивающие вероятность развития основного заболевания, в то время как коморбидные расстройства, также имеющие совокупное значение в развитии гнойного гидраденита, - это сопутствующие патологические состояния макроорганизма, не связанные с развитием хронического аутовоспаления, в результате которого и развивается гнойный гидраденит (рис. 1).

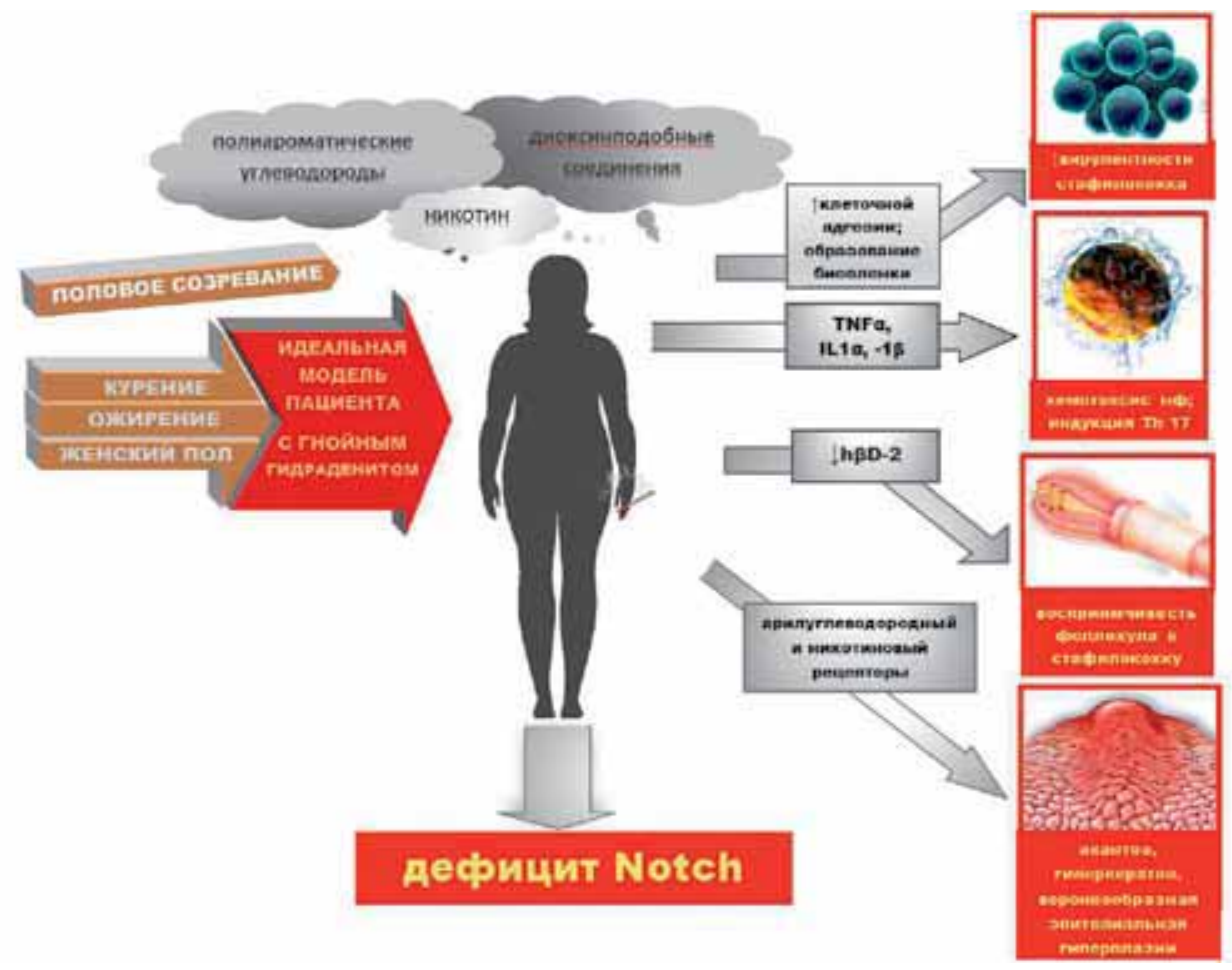

Рис. 1. Никотин, полиароматические углеводороды и диоксиноподобные соединения активируют никотиновые рецепторы ацетилхолина и арилуглеводородные рецепторы кератиноцитов и фибробластов. Табачный дым индуцирует провоспалительные цитокины, такие как TNF-a, интерлейкины 1а и $1 \beta$, что приводит к хемотаксису нейтрофилов (нф) и индукции Th17-лимфоцитов. Никотин повышает вирулентность стафилококка путем усиления клеточной адгезии и индукции образования биопленки. В то же время он ингибирует синтез антимикробных пептидов - человеческого $\beta$-десрензина-2 (hßD-2), что делает фолликул более восприимчивым к бактериальной инвазии. Сигаретный дым еще больше подавляет сигнализацию аберрантного Notch-рецептора

\section{Диагностика}

Наиболее четкое определение гнойного гидраденита в апреле 2006 г. предложил Дессау, впервые отразив в определении заболевания такие параметры, как локализация поражения, тип морфологических элементов, характеристики течения заболевания с указанием его давности, количества обострений, продолжительности ремиссии $[1,2]$.
Основными критериями диагностики гнойного гидраденита являются клинические проявления в виде болезненных узлов, часто описываемые как «слепые фурункулы», маркирующие дебют заболевания. К более поздним клиническим проявлениям относятся абсцессы, свищи или так называемые «воспаленные туннели», а также рубцы в виде «моста» и поствоспалительные «надгробные» двойные псевдокомедоны (рис. 2-5). Заболевание 
характеризуется истинным полиморфизмом элементов кожной сыпи и носит, как правило, хронический рецидивирующий характер. Диагностически незначимыми являются проявления стафилококковой инфекции, создающие некоторые сложности диффреренциального диагноза.

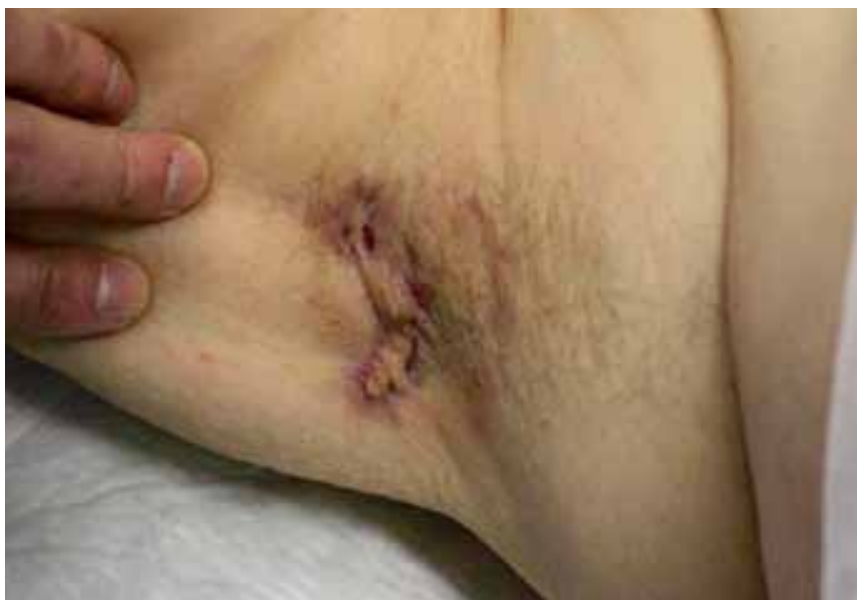

Рис. 2. Рубцы в виде «моста», свищевые ходы в фазе неполной ремиссии характеризуют картину хронического воспаления

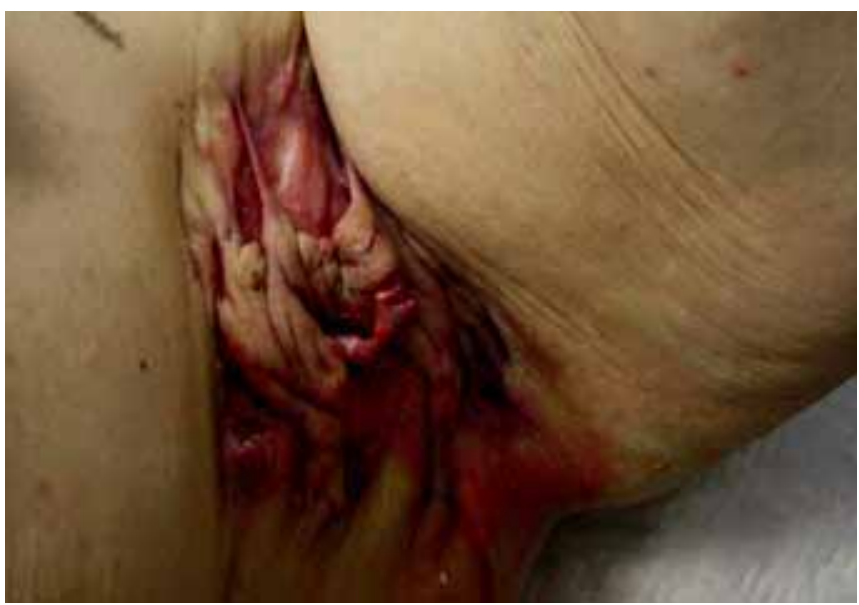

Рис. 3. Болезненные узлы, или «слепые фурункулы», являются признаком острой фазы заболевания

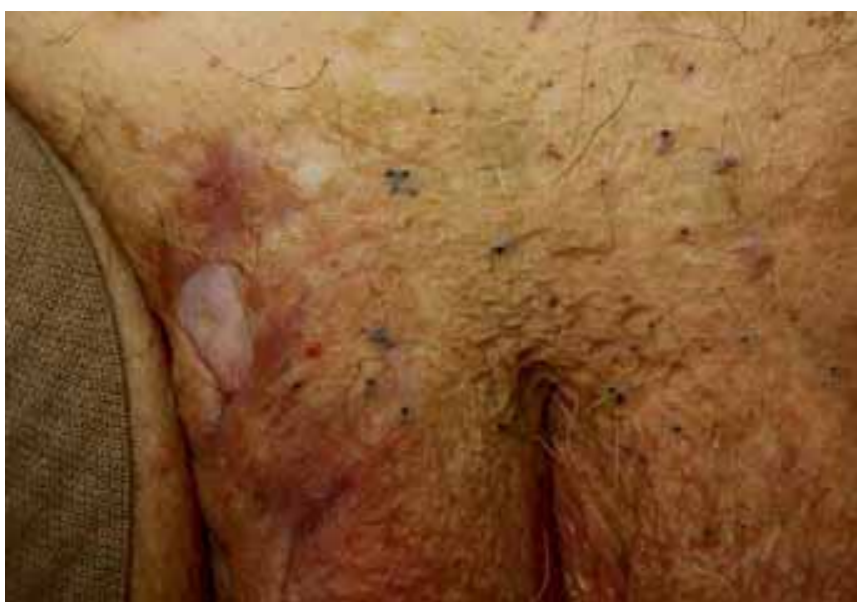

Рис. 4. Поствоспалительные двойные «надгробные» псевдокомедоны
Диагностически значимыми являются также элементы в определенных анатомических локализациях (аксиллярная и паховая области, область промежности и ягодиц, складки под молочными железами), детерминированных особенностями некоторых участков кожи и наличием в них апокриновых желез.

Данные анамнеза также должны быть отражены в клиническом уточненном диагнозе, они содержат информацию о количестве рецидивов и продолжительности заболевания. Достоверным подтверждением диагноза гнойного гидраденита являются два рецидива за последние 6 месяцев [4].

К вспомогательным критериям в дополнение к трем основным вышеперечисленным относятся: наличие гнойного гидраденита в анамнезе у родственников; рецидивирующие воспалительные высыпания, такие как фолликулит или открытые комедоны в типичных локализациях; типичные для гнойного гидраденита высыпания в нетипичных локализациях (чаще всего места трения и давления, например в области ношения ремня); наличие сопутствующей патологии - пилонидальный синус или анамнестические сведения о его существовании; отсутствие патогенной биоты в культуральном исследовании отделяемого из очага поражения.

В 2013 г. F. Canoui-Poitrine и соавт. [5] идентифицировали три варианта гнойного гидраденита. По их наблюдениям, внутри нозологической формы кардинальными отличиями между вариантами гнойного гидраденита являлись типы течения, локализация, морфологические элементы кожной сыпи и частота встречаемости. Так, первый тип - аксиллярно-маммарный - выявлялся у 48\% больных гнойным гидраденитом и характеризовался гипертрофическими рубцами, в то время как второй тип - фролликулярный - регистрировался у 26\% пациентов с гнойным гидраденитом. Наиболее типичными локализациями поражения при фолликулярном типе являлись область молочных желез, аксиллярные области, ушные раковины, область груди и спины, нижние конечности. Морфологическими элементами кожной сыпи при фолликулярном типе гнойного гидраденита были эпидермальные кисты, пилонидальные свищи, комедоны или акнефрормные элементы. Ягодичный тип также проявлялся у $26 \%$ больных гнойным гидраденитом. Поражения в виде пустул или фролликулярных папул были локализованы только лишь в ягодичной области. В последующем эта классифрикация была дополнена и заново сформирована в 6 отдельных подтипов гнойного гидраденита:

- регулярный;

- $\quad$ фрикционный фрурункулезный;

- рубцующий фолликулярный;

- конглобатный;

- синдромальный;

- эктопический [6].

\section{Оценка степени тяжести заболевания}

Определение тяжести заболевания является одним из ключевых аспектов успешной терапевтической стратегии, позволяющей добиться высокого качества жизни больных с данной патологией. Кроме этого, стадирование позволяет объективизировать степень клинического ответа и вовремя изменить план лечения, переходя от одной линии терапии к другой.

- Стадирование по Хёрли.

Впервые оценку тяжести гнойного гидраденита в 1989 г. предложил Хёрли. 
І стадия - образование одного или нескольких абсцессов без свищей и рубцов.

II стадия - рецидивирующие абсцессы с образованием свищей и рубцов, единичные или множественные, а также поражение в нескольких анатомических областях.

III стадия - дифффузные или распространенные высыпания, сообщающиеся свищевые ходы на всей площади очага поражения.

Наиболее распространенной является I стадия заболевания по Хёрли, которая регистрируется у 68\% больных гнойным гидраденитом, тогда как II стадия отмечается у $28 \%$ пациентов с данной патологией. Всего лишь $4 \%$ больных гнойным гидраденитом находятся в III стадии заболевания [7].

Удобная и легкая методика стадирования по Хёрли широко распространена в практике врача-дерматолога, однако эта система оценки отнюдь не является оптимальной. Так, например, она не может быть использована в практике хирургического стационара, вовлекающегося в лечебный алгоритм при достижении у пациента ремиссии. Стадирование по Хёрли не отражает характера септического поражения и не позволяет учитывать степень эритемы и количество гнойного отделяемого.

Сама терминология - «стадия», но не «фраза» исключает проведение анализа согласно этой системе у больных со II и III стадиями заболевания, когда рубцевание является ключевой особенностью. Учитывая, что формирование рубца является необратимым процессом, переход в III стадию является окончательным даже в случае убедительной ремиссии. В свою очередь, иссечение реакционных фолликулов с минимальным гнойным отделяемым (I и ІІ стадии по Хёрли) является прямым показанием к лечению в хирургическом отделении, что создает некоторые противоречия.

Основанная на статистических данных система оценки не позволяет осуществлять контроль эффеективности консервативной терапии, так как наличие свищей и рубцов у пациента является прямым показанием для лечения в хирургическом отделении.

Система оценки с использованием лишь трех стадий не является точным инструментом мониторинга в условиях клинических исследований, а также не может регламентировать момент перехода консервативного лечения к хирургическому.

- Шкала Сарториуса.

Более детальная оценка степени тяжести гнойного гидраденита была сформирована датским ученым Сарториусом и соавт. [8], в дальнейшем она была модифицирована. Система позволяет точно оценивать количество эле- ментов кожной сыпи, а также учитывает их характеристики - расстояние между очагами поражения, добавляя дополнительную информативность к III стадии по Хёрли [9].

- Шкала статистической общей оценки врача (PGA).

Эта 6-ступенчатая система оценки тяжести гнойного гидраденита была сформирована для использования во II фразе клинических исследований [10].

Степень «чистая» - нет воспалительных или невоспалительных узлов.

Степень «минимальная» - присутствуют единичные невоспалительные узлы.

Степень «умеренная» - менее 5 воспалительных узлов без абсцессов и функционирующих свищей или 1 абсцесс или активный свищ без дополнительных воспалительных узлов.

Степень «средняя» - менее 5 воспалительных узлов или 1 абсцесс, либо активный свищ и 1 или более воспалительных узлов, или от 2 до 5 абсцессов либо свищей и менее 10 воспалительных узлов.

Степень «тяжелая» - от 2 до 5 абсцессов или активных свищей и более 10 воспалительных узлов.

Степень «очень тяжелая» - более 5 абсцессов или дренирующих свищей.

- Индекс степени тяжести гнойного гидраденита.

Индекс степени тяжести гнойного гидраденита был создан Керделем и соавт. [11] и является специфической оценкой степени тяжести гнойного гидраденита. В этот индекс включены как объективные характеристики гнойного гидраденита, так и субъективная оценка самого пациента $[11,12]$.

- Шкала клинического ответа гнойного гидраденита.

Совсем недавно была разработана и утверждена одна из самых точных систем оценки тяжести гнойного поражения - клинический ответ гнойного гидраденита (HiSCR) [13]. Она была разработана на основе данных, собранных с помощью шкалы PGA, описанной ранее, и данных II фазы клинического исследования, к которой она была применена [14]. Система отражает степень поражения в виде снижения на $50 \%$ и более количества элементов (сумма абсцессов и воспалительных узлов), а также отсутствие фракта увеличения абсцессов или свищей (хронические воспалительные высыпания) при гнойном гидрадените по сравнению с исходным уровнем [15].

Таким образом, оценка степени клинического ответа в лечении гнойного гидраденита является одной из актуальных проблем современной дерматологии, которая нуждается в оптимизации и последующем внедрении в повседневную практику врача-дерматолога и хирурга. 


\section{Литература/References}

1. Kurzen H., Kurokawa I., Jemec G. B. et al. What Causes Hidradenitis Suppurativa? Exp. Dermatol. 2008;17(5):455-456.

2. Jemec G. B. The Symptomatology of Hidradenitis Suppurativa in Women. Br. J. Dermatol. 1988;119(3):345-350.

3. Melnik B. C., Plewig G. Impaired Notch-MKP-1 Signalling in Hidradenitis Suppurativa: an Approach to Pathogenesis by Evidence from Translational Biology. Exp. Dermatol. 2013;22(3):172-177.

4. Zouboulis C. C., Desai N., Emtestam L. et al. European S1 Guideline for the Treatment of Hidradenitis Suppurativa/Acne Inversa. J. Eur. Acad. Dermatol. Venereol. 2015;29(4):619-644.

5. Canoui-Poitrine F., Le Thuaut A., Revuz J. E. et al. Identification of Three Hidradenitis Suppurativa Phenotypes: Latent Class Analysis of a CrossSectional Study. J. Invest. Dermatol. 2013;133(6):1506-1511.

6. Poli F., Wolkenstein P., Revuz J. Back and Face Involvement in Hidradenitis Suppurativa. Dermatology. 2010;221(2):137-141.
7. Canoui-Poitrine F., Revuz J. E., Wolkenstein P. et al. Clinical Characteristics of a Series of 302 French Patients with Hidradenitis Suppurativa, with an Analysis of Factors Associated with Disease Severity. J. Am. Acad. Dermatol. 2009;61(1):51-57.

8. Sartorius K., Lapins J., Emtestam L., Jemec G. B. Suggestions for Uniform Outcome Variables when Reporting Treatment Effects in Hidradenitis Suppurativa. Br. J. Dermatol. 2003;149(1):211-213.

9. Freysz M., Jemec G. B., Lipsker D. A Systematic Review of Terms Used to Describe Hidradenitis Suppurativa. Br. J. Dermatol. 2015;173(5):1298-1300

10. Kimball A. B., Kerdel F., Adams D. et al. Adalimumab for the Treatment of Moderate to Severe Hidradenitis Suppurativa: a Parallel Randomized Trial. Ann. Intern. Med. 2012;157(12):846-855.

11. Grant A., Gonzalez T., Montgomery M. O. et al. Infliximab Therapy for Patients with Moderate to Severe Hidradenitis Suppurativa: a Randomized,

Информация об авторах

Анатолий Николаевич Родионов - д.м.Н., профессор кафредры дерматовенерологии Северо-Западного государственного медицинского университета им. И. И. Мечникова Министерства здравоохранения Российской Федерации

Алексей Владимирович Соболев - д.м.Н., профессор кафедры Научно-исследовательского института медицинской микологии им. П. Н. Кашкина Северо-Западного государственного медицинского университета им. И. И. Мечникова Министерства здравоохранения Российской Федерации

Сергей Владиславович Скрек - к.м.Н., ассистент кафедры дерматовенерологии Северо-Западного государственного медицинского университета им. И. И. Мечникова Министерства здравоохранения Российской Федерации

Пьер Волькенштейн - заведующий кафредрой, Дерматологическая служба университетского госпиталя Энри Мондор

Анастасия Александровна Юновидова — врач-дерматовенеролог Клиники кожных болезней Пьера Волькенштейна; e-mail: anastasia.yunovidova@gmail.com

\section{Information about the authors}

Anatoliy N. Rodionov - D.Sci. (Medicine), Professor of the Department of Dermatovenereology of the North-Western State Medical University named after I. I. Mechnikov, Ministry of Health of the Russian Federation

Alexey V. Sobolev - D.Sci. (Medicine), Professor of the Department of the Research Institute of Medical Mycology named after P. N. Kashkin of North-Western State Medical University named after I. I. Mechnikov, Ministry of Health of the Russian Federation

Sergey V. Skrek - PhD (Medicine), Assistant of the Department of Dermatovenereology of the North-Western State Medical University named after I. I. Mechnikov, Ministry of Health of the Russian Federation

Pierre Wolkenstein - Head of the Department, Dermatological Service of the Henri Mondor University Hospital

Anastasiya A. Yunovidova — Dermatovenereologist of the Pierre Wolkenstein French Dermatological Clinic; e-mail: anastasia.yunovidova@gmail.com 